\title{
Is there any justification for the routine examination of bowel resection margins in colorectal adenocarcinoma?
}

\author{
S S CROSS, A D BULL, J H F SMITH \\ From the Department of Histopathology, Northern General Hospital, Sheffield
}

SUMMARY The proximal and distal bowel resection margins of 339 specimens of colorectal adenocarcinoma were examined for the presence of tumour. In only five cases was tumour found in a resection margin. In four of these cases macroscopic examination showed that the tumour extended to the resection margin. In the fifth case the tumour was present in the pericolic fat. These results and reported data on the intramural spread of colorectal cancer suggest that examination of bowel resection margins is unnecessary unless the tumour extends to within $2 \mathrm{~cm}$ of the resection margin. Examination of the deep radial margins of the tumour and slides to show other prognostic indicators would be a more effective use of histopathological resources.

Examination of resected colorectal carcinomas yields useful prognostic information. Dukes showed the value of pathological staging, ${ }^{12}$ and others have shown the use of histological grading and other variables. ${ }^{3-5}$ One of the most important assessments is the adequacy of tumour excision; if a carcinoma extends to a resection margin then death from recurrent carcinoma is highly likely. ${ }^{6}$ In most laboratories circumferential samples of the proximal and distal bowel resection margins are examined microscopically without regard for the distance between these margins and the tumour. Some authors have suggested that examination of these margins is unnecessary unless the tumour is close to the margins, but there do not seem to be any published data to support this. Blenkinsopp et al stated that if the carcinoma extends to within $1 \mathrm{~cm}$ of a margin then the margin should be examined microscopically, ${ }^{7}$ but they only refer to a personal communication to justify this. Jass and Morson suggested a minimum distance of $3 \mathrm{~cm}$ but do not give any supportive data. ${ }^{5}$ Black and Waugh examined the longitudinal intramural spread of colorectal cancers and found a maximum spread of $17 \mathrm{~mm} .{ }^{8}$ They suggested that a $2 \mathrm{~cm}$ surgical margin would be adequate for complete local excision, but they did not make any recommendations for examination of surgical specimens. A similar study by Williams et al found an intramural spread of more than $1 \mathrm{~cm}$ in only $10 \%$ of the specimens they examined. ${ }^{9}$ In this paper we investigate the value of routine examination of the proximal and distal bowel margins in specimens of resected colorectal adenocarcinomas.

Accepted for publication 25 May 1989

\section{Material and methods}

The records of all bowel resections for colorectal adenocarcinomas received at the Northern General Hospital between 1984 and 1988 were reviewed. The following information was extracted from these records: distance between the macroscopically defins lateral edges of the tumour and both bowel resection margins after fixation in formalin; any other abnormalities reported in resection margin samples and Dukes' staging of the tumour. The slides of all the bowel resection margins were reviewed independently by two of the authors (SSC and ABD).

\section{Results}

A total of 371 bowel resections for colorectal adenocarcinoma were received during the study period. Fourteen of these were excluded from further study because the distance between the tumour and the resection margins had not been recorded; 18 cases were excluded because slides of the resection margins were not available for examination. Of the remaining 339 specimens, $176(52 \%)$ came from men and 163 (48\%) from women; 31 (9\%) were Dukes' stage A, 198 (59\%) Dukes' stage B, and 110 (32\%) Dukes' stage C. The distances between the tumours and resection margins in the different types of specimens are given in table 1 (standard deviations are not given because the data do not have a normal distribution).

In five of the $\mathbf{3 3 9}$ specimens tumour was found in a bowel resection margin. The details of these cases are given in table 2. In three of these cases (cases 3-5) the bowel resection was a palliative procedure and the 
Table 1 Distances between tumour and resection margins

\begin{tabular}{llll}
\hline & & \multicolumn{2}{c}{ Mean distance from lateral margin of tumour to: } \\
\cline { 3 - 5 } Type of specimen & Number of specimens & $\begin{array}{l}\text { Nearest bowel resection } \\
\text { margin }(\mathrm{cm})\end{array}$ & $\begin{array}{l}\text { Furthest bowel resection } \\
\text { margin }(\mathrm{cm})\end{array}$ \\
\hline Subtotal or total colectomy & 19 & 14 & 68 \\
Right hemicolectomy & 97 & 9 & 22 \\
Transverse colectomy & 2 & 5 & 6 \\
Left hemicolectomy & 26 & 10 & 14 \\
Sigmoid colectomy & 88 & 4 & 14 \\
Anterior resection & 64 & 6 & 24 \\
Abdominoperineal resection & 43 & &
\end{tabular}

Table 2 Details of cases with tumour present in resection margin

\begin{tabular}{|c|c|c|c|c|c|c|}
\hline \multirow[b]{2}{*}{$\begin{array}{l}\text { Case } \\
\text { No }\end{array}$} & \multirow[b]{2}{*}{ Type of specimen } & \multirow[b]{2}{*}{$\begin{array}{l}\text { Dukes' } \\
\text { stage }\end{array}$} & \multicolumn{4}{|l|}{ Distance from tumour to: } \\
\hline & & & $\begin{array}{l}\text { Proximal bowel resection } \\
\text { margin }(\mathrm{cm})\end{array}$ & $\begin{array}{l}\text { Tumour } \\
\text { present? }\end{array}$ & $\begin{array}{l}\text { Distal bowel resection } \\
\text { margin }(\mathrm{cm})\end{array}$ & $\begin{array}{l}\text { Tumour } \\
\text { present? }\end{array}$ \\
\hline $\begin{array}{l}1 \\
2 \\
3 \\
4 \\
5\end{array}$ & $\begin{array}{l}\text { Right hemicolectomy } \\
\text { Right hemicolectomy } \\
\text { Sigmoid colectomy } \\
\text { Anterior resection } \\
\text { Anterior resection }\end{array}$ & $\begin{array}{l}\mathrm{C} \\
\mathrm{C} \\
\mathrm{B} \\
\mathrm{C} \\
\mathrm{C}\end{array}$ & $\begin{array}{r}35 \\
17 \\
6 \\
14 \\
20\end{array}$ & $\begin{array}{l}\text { No } \\
\text { Yes } \\
\text { No } \\
\text { No } \\
\text { No }\end{array}$ & $\begin{array}{r}0 \\
12 \\
0 \\
0 \\
0\end{array}$ & $\begin{array}{l}\text { Yes } \\
\text { No } \\
\text { Yes } \\
\text { Yes } \\
\text { Yes }\end{array}$ \\
\hline
\end{tabular}

surgeon stated on the pathology request form that excision of the tumour was incomplete. In case 2 , a right hemicolectomy specimen, the tumour was a discrete deposit in the pericolic fat of the small bowel mesentery about $1 \mathrm{~cm}$ from the bowel wall. It was impossible to determine whether this represented a lymph node completely replaced by tumour or an extranodal deposit of tumour. In this case the surgeons noted mesenteric spread at the time of operation and put this information on the pathological request form. This tumour was Dukes' stage C with many lymph node metastases.

In six cases other abnormalities in the resection margin samples were recorded in the initial pathological report. Three reports noted melanosis coli in a resection margin and the other three mentioned mild inflammatory changes in the proximal resection margins of specimens containing obstructing carcinomas.

\section{Discussion}

The proportion of tumours in each Dukes' stage found was comparable with the findings of other studies, ${ }^{2310}$ confirming that our population of specimens was similar to that of other laboratories.

In most of the specimens the tumour was separated from the resection margins by a distance of some centimetres; only in the distal resection margins of low anterior resections was the distance between tumour and margin commonly reduced to a distance where intramural spread of the tumour might extend to the resection margin (table 1). In four of the cases (cases 1, $3,4,5$ ) where carcinoma was detected microscopically in a bowel resection margin the tumour was noted to extend to that margin on macroscopic examination. In case 2 the deposit of tumour in the pericolic fat did not provide any further information about the extent of tumour spread, the sampling of lymph nodes having the presence of multiple metastatic tumour deposits. The other information derived from examining the resection margins (melanosis coli and mild inflammation) was very unlikely to have influenced clinical management.

The results of this study indicate that routine microscopic examination of bowel resection margins is unnecessary. Data from studies of intramural spread in colorectal adenocarcinomas ${ }^{89}$ suggest that a distance of $2 \mathrm{~cm}$ from the lateral margin of the tumour to the resection margin would be a suitable point below which microscopic examination of the resection margin should be performed. Shrinkage of up to $50 \%$ has been described during fixation of colorectal specimens ${ }^{11}$ so this distance would be larger in fresh specimens. In our laboratory this practice would result in an annual saving of roughly 150 slides; this reduction would be greater if the practice were to be adopted by other institutions. Quirke et al found tumour extension to the deep radial margins of excision in $27 \%$ of a series of rectal carcinomas. ${ }^{12}$ Assessment of this margin, and examination for other prognostic indicators, such as vascular invasion, ${ }^{10}$ seem to be a more effective use of histopathological resources than routine examination of bowel resection margins. 


\section{References}

1 Dukes CE. The classification of cancer of the rectum. J Pathol Bacteriol 1932;35:323-32.

2 Dukes CE, Bussey HJR. The spread of rectal cancer and its effect on prognosis. Br J Surg 1958;12:309-20.

3 Jass JR, Atkin WS, Cuzick J, et al. The grading of rectal cancer: historical perspectives and a multivariate analysis of 447 cases. Histopathol 1986;10:437-59.

4 Jass JR, Love S, Northover JMA. A new prognostic classification for rectal cancer. Lancet 1987;i:1303-6.

5 Jass JR, Morson BC. Reporting colorectal cancer. J Clin Pathol 1987;40:1016-23

6 Floyd CE, Stirling CT, Cohn I. Cancer of the colon, rectum and anus; review of 1687 cases. Ann Surg 1966;163:829-37.

7 Blenkinsopp WK, Stewart-Brown S, Blesovsky L, Kearney G, Fielding LP. Histopathology reporting in large bowel cancer. $J$ Clin Pathol 1981;34:509-13.

8 Black WA, Waugh JM. The intramural extension of carcinoma of the descending colon, sigmoid and rectosigmoid; a pathologic study. Surg Gynecol Obstet 1948;87:457-61.

9 Williams NS, Dixon MF, Johnston D. Reappraisal of the 5 centimetre rule of distal excision for carcinoma of the rectum: a study of distal intramural spread and of patients' survival. $B r J$ Surg 1983;70:150-4.

10 Talbot IC, Ritchie S, Leighton MH, Hughes AO, Bussey HJR, Morson BC. The clinical significance of invasion of veins by rectal cancer. Br J Surg 1980;67:439-42.

11 Weese JL, O'Grady MG, Ottery FD. How long is the five centimeter margin? Surg Gynecol Obstet 1986;163:101-3.

12 Quirke P, Durdey P, Dixon MF, Williams NS. Local recurrence of rectal adenocarcinoma due to inadequate surgical resection. Histopathological study of lateral tumour spread and surgical excision. Lancet 1986;ii:996-9.

Requests for reprints to: Dr S S Cross, Department of Histopathology, Northern General Hospital, Herries Road, Sheffield S5 7AU, England. 